\title{
Strategic Management System for Competitive Business Performance in the United Arab Emirates
}

\author{
Edgar N. Barrozo ${ }^{1}$, Genaro V. Japos ${ }^{2}$, Eduardo P. Malagapo ${ }^{3}$, Ivy Corazon A. Mangaya-ay 4 \\ ${ }^{1}$ Philippine Christian University, Abu Dhabi, UAE \\ ${ }^{2}$ Saint Michael College of Caraga \\ ${ }^{3}$ EPM \& Associates, Dubai \\ ${ }^{4}$ Bohol Island State College https://orcid.org/0000-0002-1051-203X \\ 1edgar_gae@yahoo.com
}

\begin{abstract}
An organizational business strategy's primary purpose is to achieve good financial performance, commitment to customer satisfaction, and competitive business performance to sustain the enterprise's profitability and business continuity effectively. This study aims to determine the strategic management system components in predicting financial performance, commitment to customer satisfaction, and competitive business performance. The method used was the descriptive quantitative type of research employing the structured survey questionnaire to apply the Likert Scale. To the study's answer, survey questionnaires were distributed to the respondents, namely business owners, CEOs, managers, engineers, working professionals, and rated them using the Likert Scale. They were asked to rate the following independent variables as planning, risk analyzing, organizing, performing, evaluating, realigning related to the strategic management system for financial performance and commitment to customer satisfaction competitive business performance. Based on the result and findings, the effect of the variables performing, evaluating, and realigning financial performance is significant: $F=86.338 ;(\mathrm{p}=0.001,0.005$, and 0.001). Therefore, the strategic management system components, namely performing, evaluating, and realigning, are useful predictors of financial performance. The influence of the variables planning, evaluating, and realigning on the commitment to customer satisfaction is significant, and these are $\mathrm{F}=76.308$; $(\mathrm{p}=0.001,0.025,0.000)$ respectively. It can be concluded that the strategic management system components, namely planning, evaluating, and realigning, are useful predictors of commitment to customer satisfaction. The four combinations of independent variables, namely risk analyzing, organizing, performing, and evaluating competitive, are significant to competitive business performance: $F=94.82$ : $(p=0.000,0.001,0.001$, 0.000). The four variables account for $84 \%$, which indicates high accuracy prediction from the four variables. Finally, strategic management system components, namely, planning, risk analyzing, organizing, performing, evaluating, and realigning, can effectively predict financial performance, commitment to customer satisfaction, and competitive business performance. Therefore, it is recommended to use the PROPER strategy components by all business owners and practitioners to effectively execute their operations and activities on whatever business model or venture they wanted to start by creating appropriate policies and procedures to ensure its business continuity, profitability, sustainability, and growth.
\end{abstract}

Keywords

Strategic Management System, Planning, Risk Analyzing, Organizing, Performing, Evaluating, Realigning, Financial Performance, Customer Satisfaction, Competitive Business Performance, United Arab Emirates

Article Received: 10 August 2020, Revised: 25 October 2020, Accepted: 18 November 2020

\section{Introduction}

To effectively sustain and improve the financial performance, commitment to customer satisfaction, and competitiveness of business ventures are the objectives of all practicing small, medium, and large businesspeople. Since then and until today, strategic management was commonly used for all problem's resolution, and a company's strategic business plan_is the road map to ensure reaching the objective successfully (Fred David 2017). To support this, one of the essential management elements is planning, organizing, motivating, and controlling (Szopik, 2016). The involvement of decision-making and action during the process will lead to the achievement of specific objectives. Do not forget the assessment of risk and its effect to the business. Analyzing the risk before making decisions 2400 years ago is practiced by Athenians (Bernstein,1996; Aven, 2016). However, the risk analysis and mitigation method as a tool and technique to prevent significant effects in business are young, not more than 30-40 years old. Risk analysis and mitigation planning are essential to determine problems that could cause harm to business, analyze occurrence and frequency, create an action plan to prevent the risks and that you cannot avoid then minimize them (Watt, 2014). We need to organize our business. To acquire coordinated effort by defining task and authority relationships is the purpose of organizing (Fred David,2017). By determining what to do, who will do, and who reports to whom means organizing. It is essential to reach business goals through CEOs and managers; even careful planning can go to waste if organizing the company's assets and resources is not adequate. According to (H. Fayol 1916, Godwin, 2017), "To manage is to do planning and forecasting, coordinating and controlling, commanding, and organizing." We must perform our duties in the firm. The overall system fails if any one component fails to perform (Heizer, 2016). Each specific job is performed by individual interrelated components that compose one system. The operations manager must initiate change as the product move into their life cycle (introduce, grow, mature, retire) (Jay Heizer, 2016; Sraders, 2019). There are available techniques for both products and services that aid in performing this activity efficiently. We must evaluate our business operations. According to Fred David 2017, an 
organization's well-being depends on evaluating strategy; the management can be alerted before a potential problem occurs by the on-time evaluation process. Based on the study, identifying and taking corrective action when strategy initiatives are failing is to adopt an essential strategy evaluation process. (Nwachukwu, 2019). The weaknesses in the implemented strategic plan can be highlighted and make the entire process start again by using strategy evaluation. (Ivancic, 2013) Moreover, (Kumar, 2015) supports that strategy evaluation's vital activity is to determine if strategy execution meets the company goals. We must re-align business strategy.

At present, we are at the industrial revolution of 4.0 crossroads. During the past decades, economic growth and social progress were created by globalization, technology, and digitalization that worked as a system, but maintaining their form is not sustainable as we cannot bring them back to how things should be. An ongoing misalignment between business, economy, and acceptable societal results are due to present economic and political sudden change (Kelly and Sheppard, 2017). To better meet human needs, we must realign our policies and organizational systems to address these issues. Firms with aligned business and marketing strategies demonstrated a significantly more reliable overall performance than those not aligned business and marketing strategies (Eric Olson, 2018). Furthermore, the effect of the Covid-19 pandemic has informed most stakeholders on how to improve conditions for flexible employment relationships in the long-term perspective by examining businesses and workforce experiences during the period (Daniel Spurk, 2020). The organization can use these experiences as parameters to align their structures and services towards sustainability by avoiding workers layoffs through support, enhancing their work performance, and improving the workforce quality results. It also highlights the health safety risk and opportunities of flexible employment relationships and understands stakeholders' essential roles such as IoT platforms, private and local government offices in directing business continuity in flexible working relationships.

As mentioned in the previous discussions above, there are six (6) strategic management system components introduced by the researcher namely: planning, risk analyzing, organizing, performing, evaluating, and re-aligning to effectively sustain and improved the business performance. Therefore, this study aims to determine the strategic management system components in predicting financial performance, commitment to customer satisfaction, and competitive business performance in the United Arab Emirates

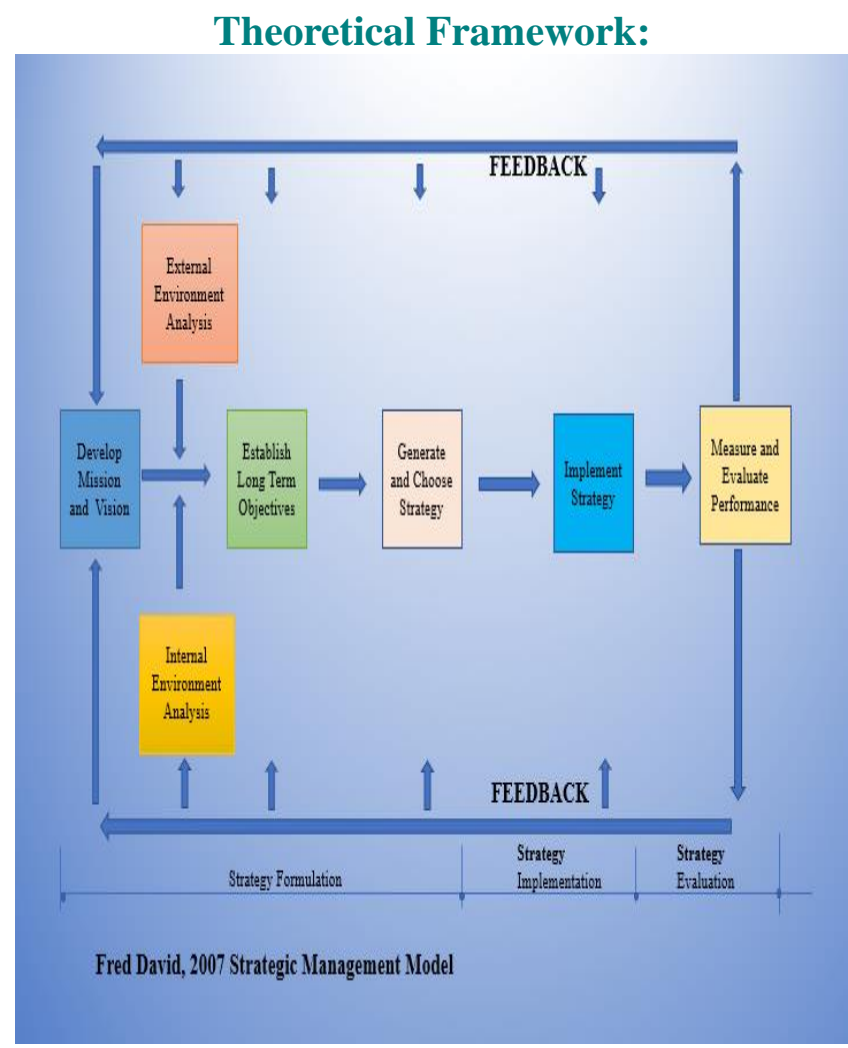

Figure - 1

The researcher cited Strategic Management (Fred David, $2007,2017)$ to support this research work. In this study, the critical success factors, or proper strategy to effectively implement and sustain the financial performance, commitment to customer satisfaction, and competitive business performance throughout the United Arab Emirates, is defined. These independent variables are planning, risk analyzing, organizing, performing, evaluating, realigning, as illustrated in the figure below.

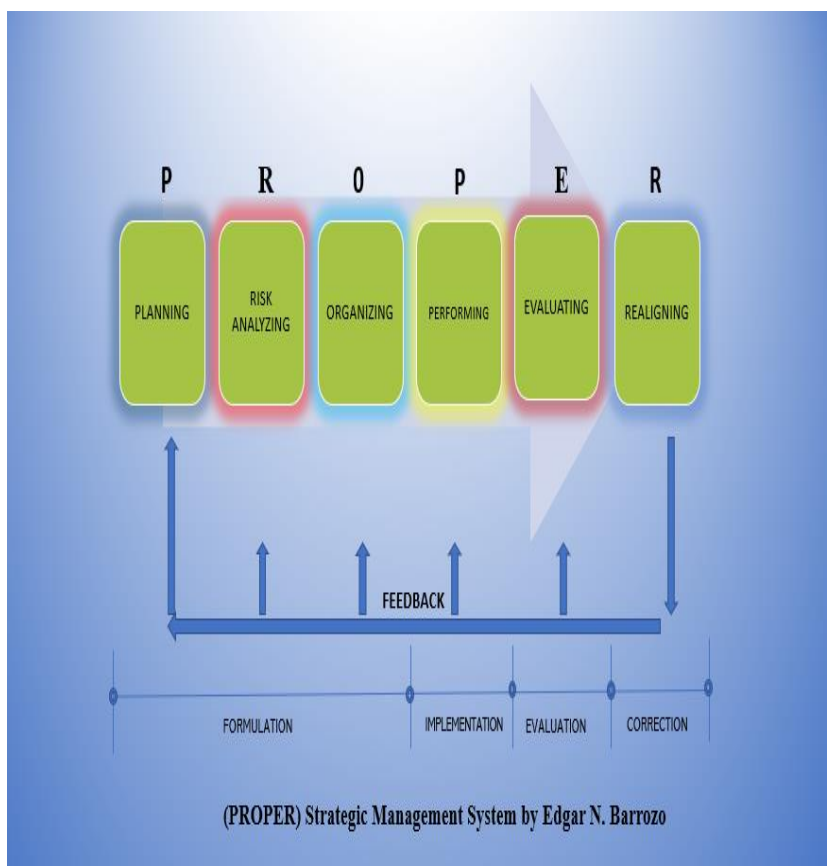

Figure - 2

Strategic Management System (Barrozo E.N. 2021) 


\section{Conceptual Framework:}

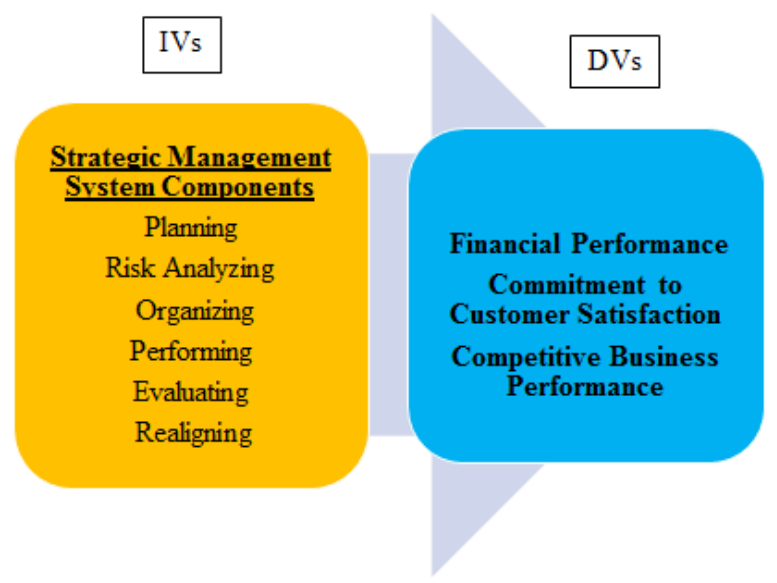

Figure - 3

The above conceptual framework is the result of the theoretical framework shown in figure 1. The researcher utilized the (IVs) six (6) components of the strategic management system with the Acronym "PROPER" (Planning, Risk analyzing, Organizing, Performing, Evaluating, and Realigning) as predictors, and including the (DVs) Financial Performance, Commitment to Customer Satisfaction, and Competitive Business Performance.

\section{Research Paradigm:}

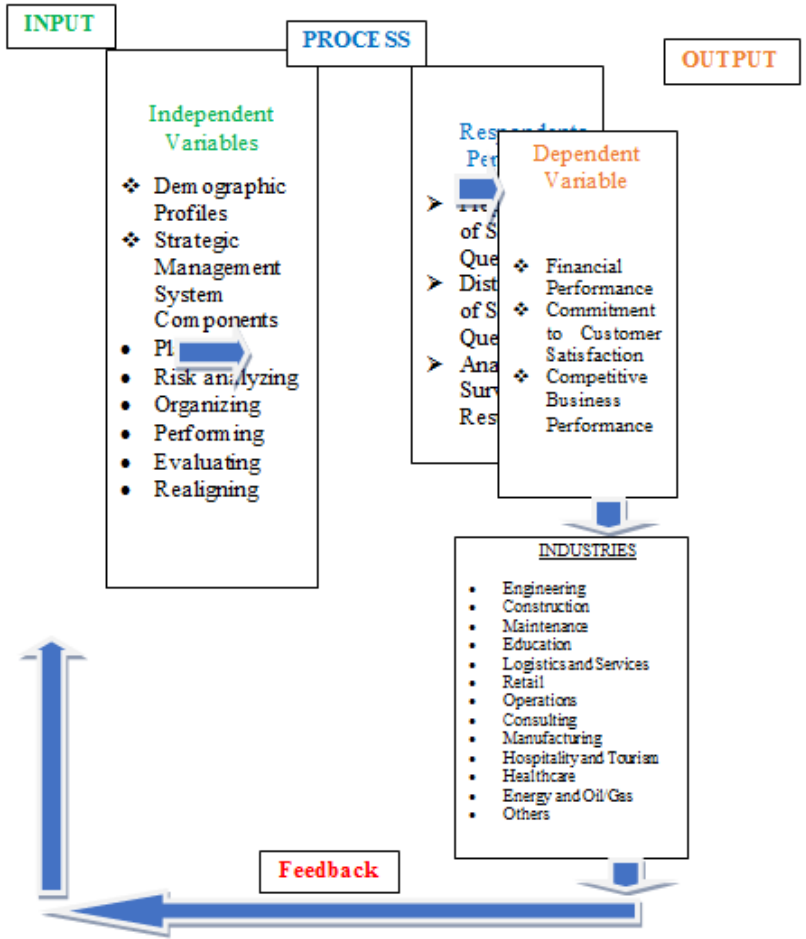

Figure -4

The above research paradigm is the result of the conceptual framework shown in figure 3 with the inputs on the Independent Variables, the process and output as Dependent Variables shown.

\section{Objectives of the Study}

This study aims to determine the strategic management system components in predicting financial performance, commitment to customer satisfaction, and competitive business performance.

\section{Methodology}

This study has demonstrated the elements in research methodology, research environment, research design, respondents of the study, population and sampling procedure, research instrument, data gathering, and data analysis techniques / statistical tools.

\section{Research Design}

The research design was a Descriptive Quantitative Research that utilized survey questionnaires using the Likert Scale (Creswell, 2014) to provide a numeric description of the selected respondents' attitudes, trends, or opinions.

\section{Research Environment}

This research was conducted in the United Arab Emirates. The researcher conducted the study in the following group of people working in various industries, namely (Group 1: TML- Top Management Level- CEOs, Directors, Vice Presidents, Business Owners, and Managers), (Group 2: ESEngineers and Specialists), (Group 3: WP- Working Professionals).

\section{Respondents of the Study}

The distributed the survey questionnaires and collected data responses was received by the researcher from 108 selected respondents working with private companies and those who are having private business in the United Arab Emirates. The respondents participated in the quantitative data collection by participating in the survey, and the researcher acquired consent acknowledgment from respondents to participate.

- Group 1-

- Group 2-

$\mathrm{TML}=19$

Group 3-

Total Population

$$
\mathrm{ES}=21
$$$$
\mathrm{WP}=68
$$$$
=108
$$

\section{Population and Sampling Procedure}

A linear regression analysis was conducted by the researcher using simple bootstrap sampling method, then made 2,000 samples and used Set Seed 4868 for Mersenne Twister with Confidence Intervals of 95\%, using IBM Statistical Package for the Social Sciences (SPSS) V25 Software.

The grouping was based on the types of respondents, namely:

- Group 1(TML- Top Management Levels such as CEOs and owner, Vice President, and Managers)

- $\quad$ Group 2 (ES- Engineers and Specialist)

- Group 3 (WP- Working Professionals) 


\section{Research Instrument}

Survey Questionnaire through Google Form, Email, Facebook Messenger, WhatsApp, and Linkedin attached with website link were utilized to deliver/collect responses; then measure/analyze the frequencies, implementation level, performance level by the used of software IBM SPSS V25 as shown below:

\begin{tabular}{|l|l|l|l|l|}
\hline $\begin{array}{l}\text { Scal } \\
\mathrm{e}\end{array}$ & $\begin{array}{l}\text { Rang } \\
\mathrm{e}\end{array}$ & $\begin{array}{l}\text { Descripti } \\
\text { on }\end{array}$ & $\begin{array}{l}\text { Interpretati } \\
\text { on }\end{array}$ & $\begin{array}{l}\text { Action to } \\
\text { be Taken }\end{array}$ \\
\hline 5 & $\begin{array}{l}4.51 \\
-5.0\end{array}$ & $\begin{array}{l}\text { Strongly } \\
\text { Agree }\end{array}$ & Very High & None \\
\hline 4 & $\begin{array}{l}3.51 \\
-4.50\end{array}$ & Agree & High & $\begin{array}{l}\text { Very Little } \\
\text { Ramificati } \\
\text { on }\end{array}$ \\
\hline 3 & $\begin{array}{l}2.51 \\
-3.50\end{array}$ & $\begin{array}{l}\text { Somewha } \\
\text { t Agree }\end{array}$ & Moderate & $\begin{array}{l}\text { Some } \\
\text { Ramificati } \\
\text { on }\end{array}$ \\
\hline 2 & $\begin{array}{l}1.51 \\
-2.50\end{array}$ & Disagree & Low & $\begin{array}{l}\text { More } \\
\text { Ramificati } \\
\text { on }\end{array}$ \\
\hline 1 & $\begin{array}{l}1.0- \\
1.5\end{array}$ & $\begin{array}{l}\text { Strongly } \\
\text { Disagree }\end{array}$ & Very Low & $\begin{array}{l}\text { Total } \\
\text { Change }\end{array}$ \\
\hline
\end{tabular}

Table 1 Likert Scale

\section{Data Gathering}

The survey was conducted by the researcher from October 2020 to November 2020, and the questionnaires were given through the distribution of survey questionnaires and google forms survey. Data was collected through a survey questionnaire using the online platform (Google Form). The survey questionnaires were based on the available survey items developed by researchers tested and proven as a useful measurement tool. The survey links were attached to emails, WhatsApp, and Facebook Messenger, and Linkedin to selected Respondents living and working in the United Arab Emirates. The survey included a Demographic Profile where respondents were asked about their socio-demographic profile, working status profile and to scale their perceptions on the independent variables. These factors were structured to be direct, concise, and short of encouraging the respondents to complete the survey. A descriptive quantitative design, bootstrap sampling, is utilized in this study. The researcher distributed the questionnaires to 19 respondents to improve the content and validate the reliability of result (Kleeman,2018). Furthermore, the Cronbach Alpha reliability test was computed at 0.91 , which suggest high reliability, as shown in the table below using IBM SPSS V25 Software.

\section{Content Validity and Reliability}

The researcher conducted the Cronbach Alpha reliability test using 19 respondents answer before proceeding further on the survey questionnaires distribution was conducted by researcher. The reliability test for the dependent variable competitive business performance averaged a Cronbach Alpha of 0.91 , indicating high reliability. All the question item scale values, when deleted, are high ranging from 0.84 to 0.94 , recommending that all items are to be retained. The calculation of Cronbach Alpha on each variable shown that the questionnaires consistency is good which indicated that questions can be used on respondents from other walks of life and locations. From the overall perspective, the reliability results 0.91 indicated that instrument is eligible as data collection tool for the research study.

Table 3.1 Calculated Cronbach Alpha, Reliability test for $\mathrm{N}=19$ Respondents:

\begin{tabular}{|c|c|c|c|c|}
\hline $\begin{array}{l}\text { Independent } \\
\text { Variables }\end{array}$ & Questionnaires & $\begin{array}{l}\text { Cronbach } \\
\text { Alpha }\end{array}$ & Interpretation & Judgement \\
\hline Planning & P1 to P10 & 0.84 & High & Retain \\
\hline Risk Ananlyzing & R1 to R10 & 0.92 & High & Retain \\
\hline Organizing & Orgl to $\operatorname{Org} 10$ & 0.94 & High & Retain \\
\hline Performing & Perl to Per10 & 0.93 & High & Retain \\
\hline Evaluating & Ev1 to Ev10 & 0.93 & High & Retain \\
\hline Realigning & Real to Rea10 & 0.85 & High & Retain \\
\hline Financial Performance & FP1 to FP10 & 0.96 & High & Retain \\
\hline $\begin{array}{l}\text { Commitment to } \\
\text { Customer Satisfaction }\end{array}$ & CS1 to CS10 & 0.92 & High & Retain \\
\hline & Result & 0.91 & High & Retain \\
\hline
\end{tabular}

\section{Data Analysis Techniques/Statistical Treatment}

All the statistical data results and discussions were validated and certified by the specialist statistician with closed supervision and guidance. Moreover, the data collected were treated using IBM Statistical Package for the Social Science (SPSS) version 25 to analyze the frequencies, descriptive statistics, correlation, and regression, and supported by Microsoft Excel to complete the process of data analysis. Whereby, the percentage was calculated from the demographic information for all participants and the respondents' perception of the strategic management system as a predictor for financial performance, commitment to customer satisfaction, and the competitive business performance of private companies. The Cronbach Alpha reliability test was conducted using 19 respondents answers before proceeding further on the survey questionnaires distribution. All the statistical data results and discussions were validated and certified by the specialist statistician with closed supervision and guidance.

\section{Results and Discussions}

This section presented the results and discussions regarding the respondents' perceptions with regards to the independent variables such as planning, risk analyzing, organizing, performing, evaluating, realigning, together with dependent variables such as financial performance, commitment to customer satisfaction, and competitive business performance. 
Table 4.6 Bootstrap Linear Regression of Financial Performance

\begin{tabular}{|c|c|c|c|c|}
\hline \multirow{2}{*}{ IV } & \multicolumn{4}{|c|}{ Regression Coefficient } \\
\cline { 2 - 5 } & $\mathrm{B}$ & Beta & $\mathrm{t}$-Value & Sig \\
\hline (Constant) & 0.811 & & 0.362 & 0.718 \\
\hline Planning & 0.111 & 0.099 & 1.405 & 0.163 \\
\hline Risk Analyzing & 0.047 & 0.046 & 0.454 & 0.651 \\
\hline Organizing & 0.205 & 0.195 & 1.693 & 0.093 \\
\hline Performing & 0.433 & 0.419 & 3.272 & 0.001 \\
\hline Evaluating & 0.344 & 0.316 & 2.865 & 0.005 \\
\hline Realigning & 0.369 & 0.355 & 3.401 & 0.001 \\
\hline
\end{tabular}

Dependent Variable: Financial Performance

Predictors: (Constant), Performing, Evaluating, Realigning If Value of Significance $<0.05$, then IV is significant.

\begin{tabular}{|c|c|}
\hline R & 0.915 \\
\hline R Square & 0.837 \\
\hline Adjusted R Square & 0.827 \\
\hline F Value for ANOVA & 86.338 \\
\hline Significance of F & 0.000 \\
\hline
\end{tabular}

The effect of the variables performing, evaluating, and realigning on financial performance is significant: $\mathrm{F}=86.338 ;(\mathrm{p}=0.001,0.005,0.001)$ respectively. Performing, evaluating, and realigning accounts for $82.7 \%$ accuracy that could be explained by the three variables. The betacoefficient of performing $(\mathrm{B}=0.433)$ is significant at $(\mathrm{p}=0.001)$, while evaluating $(\mathrm{B}=0.344)$ is significant at $(\mathrm{p}=0.005)$, and for realigning $(\mathrm{B}=0.369)$ is significant at $(p=0.001)$. Therefore, the strategic management system components, namely performing, evaluating, and realigning, are effective predictors of financial performance. A study made by (Jay Heizer 2016) concluded that performing selection, designing, defining the product, and transitioning into production is a useful product strategy. Thus, the proper implementation of this strategy can contribute to its effective production process and profitability. The research conducted by (Naser 2018) at Islamic University showed a positive impact between measuring and evaluating the performance that also achieved the objectives to control its performance from the members' perception (senior management, faculty and assistants, and members of the administrative board). Finally, a study by (Eric Olson,2018) concluded that firms with aligned business and marketing strategies demonstrated a significantly more reliable overall performance than those not aligned business and marketing strategies. Therefore, the strategic management system components, namely performing, evaluating, and realigning, are effective predictors of financial performance. Therefore, the organization's top management level should focus on formulating appropriate policies and procedures in performing, evaluating, and realigning strategies like production, operations, and marketing to achieve a significant financial performance level.
Table 4.7 Bootstrap Linear Regression of Commitment to Customer Satisfaction:

\begin{tabular}{|c|c|c|c|c|}
\hline \multirow{2}{*}{ IV } & \multicolumn{4}{|c|}{ Regression Coefficient } \\
\cline { 2 - 5 } & $\mathrm{B}$ & Beta & t-Value & Sig \\
\hline (Constant) & 2.269 & & & 0.877 \\
\hline Planning & 0.277 & 0.258 & 3.462 & 0.001 \\
\hline Risk Analyzing & 0.079 & 0.079 & 0.747 & 0.457 \\
\hline Organizing & 0.028 & 0.027 & 0.227 & 0.821 \\
\hline Performing & 0.101 & 0.102 & 0.755 & 0.452 \\
\hline Evaluating & 0.276 & 0.264 & 2.271 & 0.025 \\
\hline Realigning & 0.407 & 0.408 & 3.708 & 0.000 \\
\hline
\end{tabular}

Dependent Variable: Commitment to Customer Satisfaction Predictors: (Constant), Planning, Evaluating, Realigning

\begin{tabular}{|c|c|}
\hline R & 0.905 \\
\hline R Square & 0.819 \\
\hline Adjusted R Square & 0.809 \\
\hline F Value for ANOVA & 76.308 \\
\hline Significance of F & 0.000 \\
\hline
\end{tabular}

The influence of the variables planning, evaluating, and realigning on the commitment to customer satisfaction is significant, as shown in table 4.7, and these are $\mathrm{F}=76.308$; $(\mathrm{p}=0.001,0.025,0.000)$ respectively. The variables, namely planning, evaluating, and realigning, had given a value of adjusted R Square $=80.9 \%$, which indicate high accuracy prediction from the three variables. The beta-coefficient of planning $(B=0.277)$ is significant at $(p=0.001)$, while evaluating $(B=0.276)$ is significant at $(p=0.025)$, and for realigning $(\mathrm{B}=0.407)$ is significant at $(\mathrm{p}=0.000)$. However, among the three significant variables, realigning has the strongest coefficient. The research study made by Jan Brinckmann 2018 revealed that one of the widespread managerial practice is business planning, especially in the SME context as it produces fundamental decisions and action plans that guide an organization in shaping and realizing the goals to whom it serves, doing what business, and why doing it, with the aim of the great future.

In contrast, (Ivanic 2013) study concluded that the implemented strategic plan's weaknesses could be highlighted and make the entire process start all over again by using evaluating strategy. A study conducted by (Baig and Hall, 2020) concluded that realigning critical decision models, winning the revenue race using digital platforms, and exerting more development speed are achievable goals. These results conclude that strategic management system components, namely planning, evaluating, and realigning, are useful predictors of commitment to customer satisfaction. Therefore, the organization's top management level should focus on formulating appropriate policies and procedures in planning, evaluating, and realigning strategy on their activities like production, operations, and marketing to achieve a significant level of commitment to customer satisfaction. 
Table 4.8 Bootstrap Linear Regression of Competitive Business Performance:

\begin{tabular}{|c|c|c|c|c|}
\hline \multirow{2}{*}{ IV } & \multicolumn{4}{|c|}{ Regression Coefficient } \\
\cline { 2 - 5 } & B & Beta & t-Value & Sig \\
\hline (Constant) & 1.571 & & 0.71 & 0.479 \\
\hline Planning & 0.071 & 0.062 & 0.91 & 0.365 \\
\hline Risk Analyzing & 0.516 & 0.486 & 5.023 & 0.000 \\
\hline Organizing & 0.406 & 0.377 & 3.407 & 0.001 \\
\hline Performing & 0.444 & 0.418 & 3.394 & 0.001 \\
\hline Evaluating & 0.462 & 0.414 & 3.896 & 0.000 \\
\hline Realigning & 0.05 & 0.047 & 0.467 & 0.642 \\
\hline
\end{tabular}

Dependent Variable: Competitive Business Performance Predictors: (Constant), Risk Analyzing, Organizing, Performing, Evaluating

\begin{tabular}{|c|c|}
\hline R & 0.922 \\
\hline R Square & 0.849 \\
\hline Adjusted R Square & 0.840 \\
\hline F Value for ANOVA & 94.82 \\
\hline Significance of $\mathrm{F}$ & 0.000 \\
\hline
\end{tabular}

The four combinations of independent variables, namely risk analyzing, organizing, performing, and evaluating competitive, are significant: $F=94.82:(p=0.000,0.001$, $0.001,0.000)$. The four variables account for $84 \%$, which indicate high accuracy prediction from the four variables. The beta-coefficient for risk analyzing $(\mathrm{B}=0.516)$ is significant at $(p=0.000)$, organizing $(B=0.406)$ is significant at $(p=0.001)$, performing $(B=0.444)$ is significant at $(\mathrm{p}=0.001)$, evaluating $(\mathrm{B}=0.462)$ is significant at $(\mathrm{p}=0.000)$. However, among the four significant variables, risk analyzing and evaluating has the strongest coefficients. According to El-Sayegh 2018, identifying and assessing risk allows proper risk mitigation planning and control to be vital aspects of project risk management. A study conducted by (Viliam Lendel, 2017) concluded that the company's competitive advantage is essential in which an organized process, creation of innovative ideas, and realization is a must. While Jay Heizer 2016 concluded that the overall system fails if any one component fails to perform.

Moreover, according to Fred David's 2017 compilations of case study, an organization's well-being depends on evaluating strategy, whereby the business enterprise can be alerted before a potential problem occurs by the on-time evaluation process. Therefore, strategic management system components can effectively predict competitive business performance, namely, risk analyzing, organizing, performing, and evaluating. The business owners or top management level should formulate appropriate policies and procedures to ensure the company's business continuity, profitability, sustainability, and growth.

\section{Conclusions:}

1. The strategic management system components, such as performing, evaluating, and realigning, are regarded as the most relevant financial performance indicators.
Business organizations and top management levels in various industries should create an action plan in the performing stage to improve the process and increase the productivity rate. Develop an action plan in the evaluating stage that is more stringent to capture the gaps and minimize them through control measures. Finally, create an action plan in the realigning stage to enhance or remove unnecessary procedures or resources, and barriers during the business's operation workflow.

2. Planning, evaluating, and realigning are three components chosen as the most robust predictors that form part of the strategic management system to commit to customer satisfaction. Business owners and top management should emphasize improving their business strategy planning by enhancing customer satisfaction and creating value innovation as part of their action plan. Continually evaluating the operational workflow and method in delivering the products and services to the customers can help the management collect information that can be used for any decision making. Therefore, the company should not neglect the realigning strategy to adjust any loose policy and adopt a new working platform-style like using IoT.

3. The four components of strategy, namely, risk analyzing, organizing, performing, and evaluating, are strong predictors of competitive business performance. Therefore, business owners or top management level, and other practitioners should formulate appropriate policies and procedures and then implement them through human resources capital to ensure its business continuity, profitability, sustainability, and growth.

\section{Recommendations:}

1. Financial Performance. Business organizations and top management levels in various industries should create an action plan in the performing stage to improve the process and increase the productivity rate. Develop an action plan in the evaluating stage that is more stringent to capture the gaps and minimize them through control measures. Furthermore, create an action plan in the realigning step that would enhance or remove unnecessary procedures or resources and barriers during the business's operation workflow. This clear result evidence is shown in table 4.6, mentioning the three predictors: performing, evaluating, and realigning.

2. Commitment to Customer Satisfaction. Managers should emphasize improving their business strategy planning by enhancing customer satisfaction and creating value innovation as part of their action plan. Furthermore, continue evaluating the operational workflow and method in delivering the products and services to the customers can help collect information that can be used for decision making. Therefore, the company should not neglect the realigning strategy to adjust any loose policy and adopt a new working platform-style like using IoT. This result is shown in table 4.7, mentioning the three significant predictors: planning, evaluating, and realigning.

3. Competitive Business Performance. Those risk analyzing, organizing, performing, and evaluating strategies are vital tools and techniques to achieve C.B.P., as clearly indicated in table 4.8, mentioning the four significant predictors. The organization leaders should create an action 
plan in risk analysis to neutralize those smooth business operational flow barriers. Thus, the company must develop an effective organizational set-up system for proper works instruction, operating workflow procedures, fair staffing hierarchy, and policies. Operations manager to implement the works instruction and policies in performing their operational activities for consistency. It is highly recommended to business owners or top management level and other practitioners to formulate appropriate policies and procedures and then implement them through human resources to ensure its business continuity, profitability, sustainability, and growth.

4. Therefore, it is recommended to use the researcher's PROPER strategy by all business owners and practitioners to effectively execute their operations and activities on whatever business model or venture they wanted to start with.

The researcher also recommends that future researchers conduct further research to check the effectiveness of this PROPER strategy in terms of performance and implementation in other aspects of business, such as Employee Satisfaction and Engagement, Sales and Marketing Performance and Quality Assurance. Engineering, Human Resources Management, Asset Management, and Others. Furthermore, future researchers can utilize this proper strategic management system to determine the significant predictors for those chosen dependent variables.

\section{References}

[1] Acosta, I. C., \& Acosta, A. S. (2016). Teachers' Perceptions on Senior High School Readiness of Higher Education Institutions in the Philippines. Universal Journal of Educational Research, 4(10), 2447-2462.

[2] Aven, T. (2016). Risk assessment and risk management: Review of recent advances on their foundation. European Journal of Operational Research, 253(1), 1-13.

[3] David, F. R., David, F. R., \& David, M. E. (2017). Strategic management: Concepts and cases: A competitive advantage approach. Upper Saddle River: Pearson.

[4] David, F. R., David, M. E., \& David, F. R. (2016). How important is finance coverage in strategic management? A content analysis of textbooks. International Journal of Management and Human Resources, 4(1), 64-79.

[5] Godwin, A., Handsome, O., Ayomide, W., Enobong, A., \& Johnson, F. (2017). Application of the Henri Fayol principles of management in startup organizations. Journal of Business and Management, 19(10), 78-85.

[6] Heizer, J. (2016). Operations management, 11/e. Pearson Education India.

[7] Ioppolo, G., Szopik-Depczyńska, K., Stajniak, M., \& Konecka, S. (2016). Supply chain and innovation activity in transport related enterprises in Eastern Poland. LogForum, 12(4), 227-236.

[8] Ivančić, V. (2013). The biggest failures in managing strategy implementation. Interdisciplinary Management Research, 9.

[9] Kelly, C. O. L. M., \& Sheppard, B. (2018). Common purpose: Realigning business, economies, and society. Strategy+ Business, 88.

[10] Kumar, V. (2015). Evolution of marketing as a discipline: What has happened and what to look out for. Journal of Marketing, 79(1), 1-9.

[11] Nwachukwu, C., \& Chladkova, H. (2019). FIRM RESOURCES, STRATEGIC ANALYSIS CAPABILITY AND STRATEGIC PERFORMANCE: ORGANISATIONAL STRUCTURE AS MODERATOR. International Journal for Quality Research, 13(1).

[12] Olson, E. M., Slater, S. F., Hult, G. T. M., \& Olson, K. M. (2018). The application of human resource management policies within the marketing organization: The impact on business and marketing strategy implementation. Industrial Marketing Management, 69, 62-73.

[13] Spurk, D., \& Straub, C. (2020). Flexible employment relationships and careers in times of the COVID-19 pandemic.

[14] Uy, J. P., Japos, G. V., Mangaya-ay, I. C. A., \& Malagapo, E. P. (2020). Determinants of Career Change of Overseas Filipino Professionals in the Middle East. PalArch's Journal of Archaeology of Egypt/Egyptology, 17(1), 173-186. 